\title{
Effect of Green Tea on Haemoglobin
}

\author{
Nihal A Sachdev, Mrs.Jothipriya. \\ Professor-Department of Physiology Saveetha Dental College, Chennai- 77
}

\begin{abstract}
:
Aim: To estimate the influence of green tea on haemoglobin.

Background: Green tea, recently has become of of the most common natural health drinks in the market. Although it is flied with life-giving antioxidants, most people are unaware of the compounds like tannin and .... which is known to hinder with regular iron absorption.

Iron is one of the most essential metals, required for the normal functioning of the body. A reduction in the iron content could lead to anaemia, weakness and various other health issues.
\end{abstract}

Reason: As the popularity of tea is constantly increasing, awareness needs to be made about the negative effects of it.

Keywords: 'iron', 'tannins', 'polyphenols' 'supplements'.

\section{Introduction:}

Tea is one of the most popularly consumed beverages, worldwide. Tea is prepared from the plant Camellia sinensis. Black tea and Green tea are the most common teas consumed. The most significant effects on human health have been observed with the consumption of green tea .(1). The first green tea was exported from India to Japan during the 17th century. Although, many historians argue that tea consumption and export originated from China during the rue of emperor Shennong.(2)

It is estimated that about 2.5 million tons of tea leaves are produced each year throughout the world, with $20 \%$ produced as green tea, which is mainly consumed in Asia, some parts of North Africa, the United States, and Europe .(3). The association between tea consumption, especially green tea, and human health has long been appreciated (4.5). Green tea and black tea are processed differently during manufacturing. To produce green tea, freshly harvested leaves are immediately steamed to prevent fermentation, yielding a dry, stable product. This steaming process destroys the enzymes responsible for breaking down the color pigments in the leaves and allows the tea to maintain its green color during the subsequent rolling and drying processes. These processes preserve natural polyphenols with respect to the health-promoting properties. As green tea is fermented to Oolong and then to black tea, polyphenol compounds (catechins) in green tea are diamerized to form a variety of the flavins, such that these teas may have different biological activities. The preparatory methods of green tea also greatly influence the concentration of catechins in it. (6)

Haemoglobin (Hbs) is a member of heme associated, iron containing respiratory protein present in the red blood cells.(7). Haemoglobin is present in almost all vertebrates and also some invertebrates.(8). The main function of haemoglobinn is to transport oxygen and carbon dioxide in the circulatory system of animals. Haemoglobin also plays a role in host immunity and antioxidant and moulting regulation.(9). The major form of haemoglobin in adults is a tetrameric metalloprotein made up of two alpha and two beta chains, which are encoded by the two genes present on chromosomeme 16 and 11 respectively. (10).

\section{Materials and methods:}

The study was performed on 20 induvudials, (12 female and 8 male). initially, all the participant's haemoglobin levels were tested using a sallies hemometer and the values were carefully tabulated. The participants were then made to consume $300 \mathrm{ml}$ of green tea, on a daily basis for exactly 30 days. The haemoglobin levels of all the participants was then tested after 30 days using the san apparatus, and the values were carefully tabulated.

\section{Result and discussion:}

The haemoglobin of the participants, before and after the study was performed is tabulated below: 
Table 3

\begin{tabular}{|c|c|c|c|}
\hline S.NO & GENDER & PRE & POST \\
\hline 1 & 1 & 13 & 13 \\
\hline 2 & 0 & 11.3 & 11 \\
\hline 3 & 1 & 13.8 & 12.5 \\
\hline 4 & 0 & 11.8 & 11.2 \\
\hline 5 & 1 & 16 & 15.8 \\
\hline 6 & 0 & 10.6 & 10 \\
\hline 7 & 1 & 14 & 13.4 \\
\hline 8 & 0 & 13.5 & 12 \\
\hline 9 & 1 & 13.8 & 13.4 \\
\hline 10 & 1 & 13.5 & 12.8 \\
\hline 11 & 0 & 13.2 & 13 \\
\hline 12 & 0 & 9.8 & 9.2 \\
\hline 13 & 0 & 11.2 & 10 \\
\hline 14 & 0 & 12.6 & 12.2 \\
\hline 15 & 1 & 11.2 & 10.5 \\
\hline 16 & 0 & 10.4 & 9.8 \\
\hline 17 & 0 & 13.4 & 10 \\
\hline 18 & 0 & 12.6 & 11.8 \\
\hline 19 & 1 & 13.2 & 12.6 \\
\hline 20 & 0 & 12.8 & 11 \\
\hline & & 12.585 & 11.76 \\
\hline
\end{tabular}

Even though green tea is an excellent fat burner, it is known to reduce or inhibit various other factors such as haemoglobin, vitamin B12. it is evident that a considerable decrease in the mean haemoglobin level after the experiment is observed. This indicates that green tea consumption, over time does reduce haemoglobin levels. This is due to antioxidants like polyphenols present in the tea. These polyphenols bind with iron, inhibiting intestinal absorption. Green tea is also known to reduce the uptake of vitamin B12.

\section{GENDER $\square$ PRE $\square$ POST}

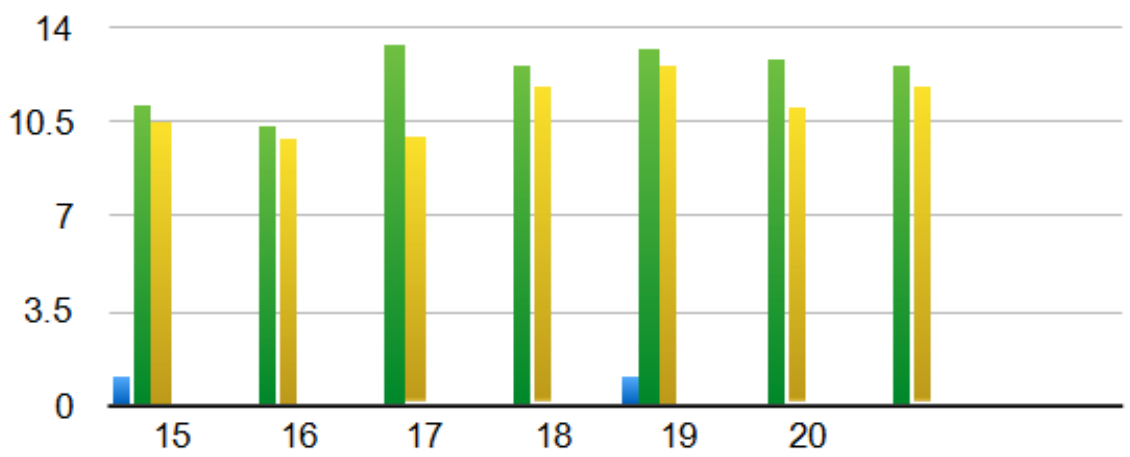

The average haemoglobin level before the study was performed was 12.58 and the average haemoglobin performed after the test was performed was 11.76 .

\section{Conclusion:}

Even though green tea is one of the best power drinks, constant comsumption of green tea can reduce haemoglobin levels and hence it is advisable to consume an iron rich diet or couple green tea consumption with iron rich supplements. Consuming iron and multivitamin supplements will not only negate the negative effects of green tea but will also allow the green tea to effectively burn fat and eliminate the circulating free radicles. 


\section{References:}

[1]. Cabrera C, Artacho R, Giménez R. Beneficial effects of green tea: a review. J Am Coll Nutr. 2006;25:79-99. [PubMed]

[2]. Dattner, Christine; Boussabba, Sophie (2003). Emmanuelle Javelle, ed. The Book of Green Tea. Universe Books. p. 13. ISBN 978-07893-0853-5.

[3]. Japanese Green Tea Online.com. http://www.japanesegreenteaonline.com

[4]. Weisburger JH. Approaches for chronic disease prevention based on current understanding of underlying mechanisms. Am J Clin Nutr. 2000;71(6):1710S-1714S. [PubMed]

[5]. Sato T, Miyata G. The nutraceutical benefit, part I: green tea. Nutrition. 2000;16:315-317. doi: 10.1016/S0899-9007(99)00301-9. [PubMed] [Cross Ref]5

[6]. Khan N, Mukhtar H (2013). "Tea and health: studies in humans". Current pharmaceutical design (Literature Review). 19 (34): 6141- 7. doi:10.2174/1381612811319340008. PMC 40553520. PMID 23448443.

[7]. Weed, Robert I.; Reed, Claude F; Berg, George (1963). "Is hemoglobin an essential structural component of human erythrocyte membranes?". J Clin Invest. 42 (4): 581-88. doi:10.1172/JCI104747. PMC 289318@. PMID 13999462.

[8]. Maton, Anthea; Jean Hopkins; Charles William McLaughlin; Susan Johnson; Maryanna Quon Warner; David LaHart; Jill D. Wright (1993). Human Biology and Health. Englewood Cliffs, New Jersey, US: Prentice Hall. ISBN 0-13-981176-1.

[9]. Jensen, Frank B (2009). "The dual roles of red blood cells in tissue oxygen delivery: oxygen carriers and regulators of local blood flow". Journal of Experimental Biology. The Company of Biologists. 212 (Pt 21): 3387-93. doi:10.1242/jeb.023697. PMID 19837879

[10]. Hardison, Ross C. (2012-12-01). "Evolution of hemoglobin and its genes". Cold Spring Harbor Perspectives in Medicine. 2 (12): a011627. doi:10.1101/cshperspect.a011627. ISSN 2157-1422. PMC 3543078 . PMID 23209182. 